\title{
The Role of Mannose-Binding Lectin in Susceptibility to Infection in Preterm Neonates
}

\author{
AGNIESZKA B. DZWONEK, OLAF W. NETH, RODOLPHE THIÉBAUT, EWA GULCZYNSKA, MARCIA CHILTON, \\ THOMAS HELLWIG, MONA BAJAJ-ELLIOTT, JANE HAWDON, AND NIGEL J. KLEIN
}

\begin{abstract}
Department of Infectious Diseases and Microbiology [A.B.D., O.W.N., R.T., M.B.-E., NJK.], University College London, WC1N 3JN, United Kingdom; Neonatal Department [E.G.], Department of Clinical Immunology [A.B.D.], Polish Mother Memorial Hospital-Research Institute, Lodz, 93-338, Poland; Neonatal Intensive Care Unit [M.C., T.H., J.H.], University College London Hospitals, London, WC1E 6BT, United Kingdom; Institut National de la Santé et de la Recherche Médicale [R.T.], U875 Biostatistics, Bordeaux, 33075 France
\end{abstract}

\begin{abstract}
Preterm neonates are susceptible to infection due to a combination of sub-optimal immunity and increased exposure to invasive organisms. Mannose-binding lectin (MBL) is a component of the innate immune system, which may be especially important in the neonatal setting. The objective of this study was to investigate the impact of MBL on susceptibility and severity of infection in preterm neonates during their first month of life. One hundred fifty eight preterm neonates were genotyped for MBL mutations by heteroduplex analyses. Consecutive serum MBL levels were measured by ELISA and clinical and laboratory data, including blood cultures, were collected for each baby. A third of the premature neonates had genetically determined MBL deficiency. In addition, MBL levels were also low in the first week of life and lower in neonates with a wild type genotype who were less than 28 wk gestation or a birth weight of less than $1000 \mathrm{~g}$, thereby increasing the number of neonates with a low MBL level at birth. MBL deficiency was associated with an increased risk of sepsis $(p<0.01)$. This study indicates that MBL levels are low in neonates at birth and renders premature neonates to an increased risk of infection. (Pediatr Res 63: 680-685, 2008)
\end{abstract}

$\mathrm{D}^{\mathrm{c}}$ espite advances in perinatal care, neonatal infection remains an important cause of morbidity and mortality, particularly among very low birth weight (VLBW) preterm infants $(1,2)$. Reported rates of infection vary considerably, but may be higher than $20 \%$ in low gestational ages (3). It would appear that this figure has not changed dramatically in the last decade.

Numerous factors are responsible for the high rate of infection in this patient population. Neonates of low gestational age and birth weight are particularly at risk of infection, in part because of the intensity of supportive care required such as mechanical ventilation, parenteral feeding, and the requirement for prolonged i.v. access. In addition, there are immunologic reasons why infection occurs. The absence of pas-

Received October 18, 2007; accepted January 16, 2008.

Correspondence: Nigel J. Klein, Ph.D., Department of Infectious Diseases and Microbiology, Institute of Child Health, University College London WC1N 3JN, United Kingdom; e-mail: n.klein@ich.ucl.ac.uk

A.B.D. and O.W.N. contributed equally to this study.

This work was supported through a Marie Curie European Individual Fellowship grant number QLK2-CT-2001-52004 (to A.B.D. MD by Research) and Marie Curie European Reintegration grant (MERG-CT-2004-011868), Brussels, European Commission. All reagents and consumables related to project implementation were financed by European Commission (grant number QLK2-CT-2001-52004).Supported by a grant from the Agence nationale de recherches sur le sida et les hépatites virales (ANRS) (to R.T.). sively derived maternal antibody such as that directed against Group B Streptococcus appears to be important $(4,5)$. Indeed premature neonates of less than $32 \mathrm{wk}$ of gestation have fetal IgG concentrations of less than $50 \%$ of maternal levels $(6,7)$. Many elements of the acquired immune system are also either low or function sub-optimally $(8,9)$. It is in these circumstances, that the innate immune system may be particularly important in providing protection against infection.

Mannose-binding lectin (MBL) is a circulating pattern recognition molecule of the innate immune system (10-12). MBL recognizes carbohydrate structures on the surface of a wide range of microorganisms including bacteria, viruses, yeasts, protozoa, and parasites $(11,13,14)$. This lectin can mediate phagocytosis and can activate the complement pathway in an antibody and C1-independent manner (15-17). Initiation of this lectin pathway follows binding, via a carbohydrate recognition domain (CRD), to mannose, $N$-acetyl glucosamine, fucose, and glucose residues present in the orientations and densities commonly found on microorganisms (12-14).

Circulating MBL concentrations are correlated with genetic variations in the structural and promoter regions of the $M B L-2$ gene (18). Three single nucleotide polymorphisms in codons 52,54 , and 57 ( $D, B$, and $C$ variants, respectively) in exon-1 of the MBL gene lead to reduced MBL concentrations (18-20). Polymorphisms in the promoter region at -221 (variants $\mathrm{X} / \mathrm{Y}$ ), and -550 (variants $\mathrm{H} / \mathrm{L}$ ), also modulate MBL concentrations $(20,21)$. MBL deficiency is common, affecting approximately a third of the population. More severe deficiency, less than $400 \mathrm{ng} / \mathrm{mL}$, occurs in about $10 \%$ of the white population $(10,20)$. Individuals deficient in MBL are more susceptible to infections, particularly in the context of another "immune defect" (22-26).

Numerous studies have now looked at MBL in the neonatal setting. Terai and Kobayashi reported that in term neonates, MBL levels increased during the first 5 days after birth (27). Thiel et al. showed that MBL levels at term were only a third of those seen at 3 mo (28). It would appear from subsequent

\footnotetext{
Abbreviations: ELBW, extremely low birth weight; MBL, mannose-binding lectin; SIRS, systemic inflammatory response syndrome; VLBW, very low birth weight
} 
publications that MBL levels are lower in preterm than term neonates and is related to gestational age rather than birth weight (29-31). However, it is unclear if MBL deficiency is clinically important in neonates. The present study was designed to investigate if low MBL levels predispose preterm neonates to infection.

\section{PATIENTS AND METHODS}

Patients. One hundred and sixty-six premature neonates of gestational age less than $<37$ wk were prospectively recruited for this study between September 2002 and June 2005. Sixty-seven were from the University College London Hospitals, NHS Trust, London, UK and 99 were from the Polish Mother Memorial Hospital, Lodz, Poland. Patients were randomly selected on the basis of availability of the research staff to obtain consent, collect and process the sample. Most patients were recruited between 2003 and 2004. Patients were randomly selected on the basis of availability of the research staff to obtain consent, collect and process the sample and are representative of the total preterm population admitted. Ethical approval was granted by the ethics committees of The Polish Mother Memorial HospitalResearch Institute, Lodz, Poland and UCLH in London. Parental consent was obtained before patient enrollment. Neonates with major congenital abnormalities or requiring surgical intervention were excluded.

MBL genotype and protein analyses. All neonates included in the study had blood taken for MBL phenotyping and genotyping. Blood was collected on days 1-3, 7-10, 14-18, and 27-30 and analyzed for MBL levels by ELISA (MBL oligomer Elisa Kit, Antibody Shop, Denmark). DNA was isolated from whole-blood samples using a QIAamp DNA blood mini kit (Crawley, UK). The genetic variants within exon-1 of the MBL gene at codon 52 (D), 54 (B) and $57(\mathrm{C})$ were determined by polymerase chain reaction (PCR) followed by heteroduplex analysis utilizing polyacrylamide gel electrophoresis (PAGE) (32-34). Wild type alleles were denoted as $\mathrm{A}$ and variant alleles as $\mathrm{O}$. Promoter polymorphisms at $-221(\mathrm{X} / \mathrm{Y})$ of the MBL gene were also determined using a similar method (32). The three $M B L-2$ structural gene mutations, $\mathrm{B}, \mathrm{C}$, and $\mathrm{D}$ are in linkage disequilibrium with the promoter region polymorphism $\mathrm{X} / \mathrm{Y}$, so that only $\mathrm{Y}$ associates with variant alleles (20).

Infection. Each neonate was followed up during the study period (days 0-30) for evidence of infection. Blood cultures were performed when infection was suspected. Definitive sepsis was diagnosed if they had the combination of a positive blood culture and clinical and/or laboratory evidence of sepsis. Clinical markers of sepsis included poor circulation (pallor, decreased perfusion, hypotension, tachycardia or bradycardia), increased oxygen requirement or ventilation parameters, temperature instability, lethargy or irritability, abdominal distension, feeding intolerance and jaundice. Laboratory markers included abnormal leukocyte count, increased immature-to-total neutrophil ratio, low platelet count, and raised C-Reactive Protein (CRP). Positive blood cultures in the absence of clinical or laboratory evidence of sepsis were considered to be contaminants and excluded from the study. Neonates were "presumed" to have sepsis if they had clinical or laboratory evidence of sepsis but without positive blood cultures. The clinical data were collected prospectively and a diagnosis of sepsis was recorded. However, to provide a more consistent evaluation of this diagnosis, the designation of a sepsis diagnosis was made by two clinicians who reviewed the notes retrospectively. They were blinded from the MBL data. In the UK cohort, the duration of antibiotic therapy used in the first $30 \mathrm{~d}$ of life was also recorded as a proxy marker of sepsis. This information was not recorded in the Polish cohort.

Statistical analysis. Patients were classified according to their MBL exon-1 mutations and their corresponding promoter allotypes as follows: Patients with either YA/YA, YA/XA, XA/XA genotype were summarized as wild-type (A/A), patients with $\mathrm{YA} / \mathrm{YD}$, YA/ $\mathrm{YB}+\mathrm{YC}, \mathrm{XA} / \mathrm{YD}$ or $\mathrm{XA} /$ $\mathrm{YB}+\mathrm{YC}$ as heterozygous $(\mathrm{A} / \mathrm{O})$ and patients with $\mathrm{YO} / \mathrm{YO} \mathrm{MBL}$ genotype were defined as homozygous $(\mathrm{O} / \mathrm{O})$. Genotype (or allele) frequencies were analyzed by the $\chi^{2}$ test. Differences between groups (MBL serum levels) were compared using the Mann-Whitney $U$ Test or Kruskal-Wallis test. Changes in mean MBL values were analyzed using a mixed effect model that took into account correlations between repeated measurements within an individual (35). All models included an intercept for measurements performed on days $1-3$, a first slope for the change to $7-10 \mathrm{~d}$ and then a second slope for the change from 7-10 $\mathrm{d}$ to the end follow-up. Then, the effect of the genotype, LBW, and low gestational age at birth on baseline and evolution of mean MBL were tested. The analyses of the risk of sepsis according to MBL level, birth weight, and gestational age at birth were performed using logistic regression.
Probability values were two-sided, and statistical significance was defined as $p<0.05$.

\section{RESULTS}

Patients' characteristics. One hundred sixty-six premature neonates (99 Polish and 67 British) were enrolled into the study. One hundred fifty-eight were included for further analysis (see below). Within this group, the mean gestational age was $30 \mathrm{wk}$ (range: $24-36 \mathrm{wk}$ ) and the mean birth weight was 1399 g (range: 510-2958 g). Ninety-five of 158 (60\%) neonates had a birth weight $\leq 1500 \mathrm{~g}$ and were classified as very low birth weight (VLBW) and 45 of 158 (28\%) had a birth weight $\leq 1000$ g (extremely low birth weight, ELBW). Fortysix of $158(29 \%)$ were neonates of gestational age $\leq 28 \mathrm{wk}$, and $81 \%$ of these were ELBW. There were no significant differences between the British and Polish cohorts in terms of sex $(p=0.93)$, gestational age $(p=0.39)$ and birth weight $(p=0.37)$.

Analysis of MBL genotype. MBL-2 genotypes were successfully determined in 158 (97 Polish and 61 British) neonates. In eight neonates, a genotyping sample was either not obtained $(n=5)$ or was insufficient $(n=3)$ for $\mathrm{MBL}$ genotyping. Table 1 shows the frequency of MBL genotypes for British and Polish neonates. There was no significant difference in the frequency of MBL genotypes between the two populations $(p=0.44)$. The distribution of MBL genotypes was similar between neonates of different gestational age and birth weight (data not shown).

MBL genotype and sepsis. Forty-seven neonates from the 158 with known MBL genotypes $(29.7 \%$ ) had a single positive blood culture during the study period which was associated with clinical or laboratory evidence of sepsis (definitive sepsis): 16 (26.2\%) were from the British cohort and 31 (31.9\%) were from the Polish population. Nine neonates had a second episode of sepsis with Coagulase negative staphylococci $n=$ 3; Enterobacter sp., $n=1$, Klebsiella sp., $n=2$, Candida albicans, $n=3$. These were not included in the analyses. The organisms isolated during the first episode of sepsis are presented in Table 2. In both populations, the majority of positive blood cultures were caused by Coagulase negative staphylo-

Table 1. Frequency of $M B L$ Exon-1 and $X / Y$ promoter polymorphisms

\begin{tabular}{lcc}
\hline MBL genotype & British neonates $n(\%)$ & Polish neonates $n(\%)$ \\
\hline YA/YA & $22(32.8)$ & $34(34.4)$ \\
YA/XA & $14(20.9)$ & $29(29.3)$ \\
XA/XA & $0(0.0)$ & $4(4.0)$ \\
Wildtype (A/A) & $36(53.7)$ & $67(67.7)$ \\
YA/YD & 0 & 5 \\
YA/YB + YC & 17 & 17 \\
XA/YD & 1 & 0 \\
XA/YB + YC & 5 & 5 \\
Heterozygous (A/O) & $23(34.3)$ & $27(27.3)$ \\
YO/YO & $2(3.0)$ & $3(3.0)$ \\
Homozygous (O/O) & $2(3.0)$ & $3(3.0)$ \\
Missing & $6(9.0)$ & $2(2.0)$ \\
Total & $67(100)$ & $99(100)$ \\
\hline
\end{tabular}

Patients with either YA/YA, YA/XA, XA/XA genotype were summarized as $\mathrm{A} / \mathrm{A} ; \mathrm{YA} / \mathrm{YD}, \mathrm{YA} / \mathrm{YB}+\mathrm{YC}, \mathrm{XA} / \mathrm{YD}$ or $\mathrm{XA} / \mathrm{YB}+\mathrm{YC}$ patients were defined as $\mathrm{A} / \mathrm{O}$ and patients with $\mathrm{YO} / \mathrm{YO} \mathrm{MBL}$ genotype as $\mathrm{O} / \mathrm{O}$. 
Table 2. Microorganisms associated with the first episode of bacteraemia

\begin{tabular}{lccc}
\hline Organisms & British & Polish & Total \\
\hline Gram-positive & 15 & 26 & 41 \\
Coagulase negative Staphylococcus & 13 & 22 & 35 \\
Staphylococcus aureus & 1 & 3 & 4 \\
Group B Streptococcus & 1 & 1 & 2 \\
Gram-negative & 1 & 4 & 5 \\
Escherichia coli & 0 & 1 & 1 \\
Klebsiella sp. & 1 & 0 & 1 \\
Enterobacter sp. & 0 & 1 & 1 \\
Haemophilus influenzae & 0 & 1 & 1 \\
Corynobacterium macginleyi & 0 & 1 & 1 \\
Fungi & 0 & 1 & 1 \\
Candida albicans & 0 & 1 & 1 \\
Total & 16 & 31 & 47 \\
\hline
\end{tabular}

The table shows the number of individual neonates in the studied cohort with positive blood cultures.

cocci. Only five blood cultures were positive for Gramnegative organisms and one for Candida albicans. No significant association was found between definitive sepsis and MBL genotype for the neonatal population as a whole $(p=$ $0.46)$. Of the 47 positive blood cultures, 42 were from VLBW neonates. Of these, 17 had variant alleles and 25 were WT. There were $53 \%$ of the VLBW neonates with variant alleles who had a definitive sepsis compared with $39 \%$ in the WT VLBW population and this just failed to reach significance $(p=0.053)$. Analyses of the effect of MBL genotype, gestational age $\leq 28 \mathrm{wk}$ and birth weight $\leq 1000 \mathrm{~g}$ also did not show a statistically significant association with sepsis. Interestingly, 4 of the 5 patients who were found to be homozygous for MBL variant alleles had definitive sepsis. There was no apparent relationship between MBL genotype and susceptibility to any specific micro organism.

In total, 80 of $158(50.6 \%)$ preterm neonates were diagnosed with sepsis, both definitive $(n=47)$ and presumed $(n=$ 33). A total of $54.6 \%$ of neonates with $M B L-2$ variants had sepsis compared with $48.6 \%$ with a wild type genotype (A/A). This was not significant $(p=0.47)$.

Ninety-five neonates were classified as VLBW. Of these, 69 $(72.6 \%)$ had a septic episode, definitive or presumed. Twentyseven out of $32(84.3 \%)$ neonates with variant alleles had a septic episode compared with 42 of $63(66.6 \%)$ with a wild type genotype. This just failed to reach significance $(p=$ 0.056). Analyses of the effect of MBL genotype, gestational age $\leq 28$ wk and birth weight $\leq 1000$ g also did not show a statistically significant association with sepsis, definitive or presumed.

MBL phenotypic analysis. MBL levels at birth and throughout the 30-d study period were measured and related to $M B L-2$ genotype, gestational age, and birth weight. One hundred thirty neonates had a sample taken within the first $3 \mathrm{~d}$ of life and 38 neonates had 4 samples collected (completed serial measurements). As expected, baseline serum MBL levels were significantly related to $M B L-2$ genotype $(p<0.001)$ (Fig. 1). MBL levels were also determined by postnatal age. Levels increased between the 1-3 d sample and the 7-10 d sample (Figs. 2 and 3). The increase between the first two samples was larger in WT neonates $(+243 \mathrm{ng} / \mathrm{mL} / \mathrm{d} 95 \%$

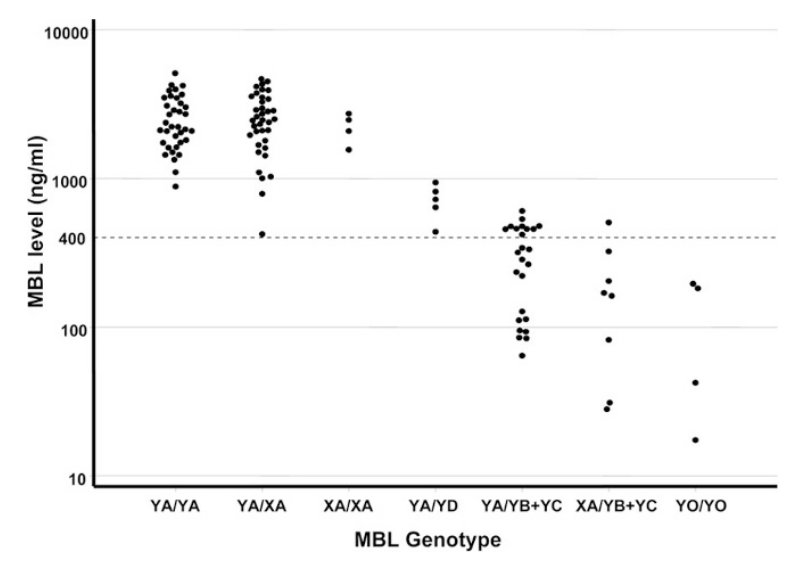

Figure 1. Correlation between MBL levels and MBL genotype. The horizontal dashed line represents MBL level of $400 \mathrm{ng} / \mathrm{mL}$.

confidence interval $[\mathrm{CI}]=+196 ;+291)$ than in neonates with MBL mutations $(+43 \mathrm{ng} / \mathrm{mL} / \mathrm{d}[\mathrm{CI}]=-17 ;+103, p<$ 0.001). This increase remained stable for the subsequent two samples. In WT neonates, baseline MBL levels were significantly lower in babies born at $28 \mathrm{wk}$ of gestational age or less (2077 versus $2627 \mathrm{ng} / \mathrm{mL}, p=0.022$ ) whereas they were not statistically significant in neonates with MBL mutations (214 versus $440 \mathrm{ng} / \mathrm{mL}, p=0.43$ ). Interestingly, the rate of change of MBL levels between the first and subsequent samples was marginally influenced by gestational age at birth during the first week, tending to be larger in neonates with lower gestational age $(+82 \mathrm{ng} / \mathrm{mL} / \mathrm{d} p=0.12)$. MBL levels in WT neonates born at less than $28 \mathrm{wk}$ therefore reached those born at greater than $28 \mathrm{wk}$ at $4 \mathrm{wk}$ postpartum (3900 versus 3956 $\mathrm{ng} / \mathrm{mL}, p=0.84)$. The difference in baseline MBL level between neonates with very low birth weight $(\leq 1500 \mathrm{~g})$ and the others were not significant either in WT $(p=0.73)$ or neonates with variant alleles $(p=0.57)$. However, in WT
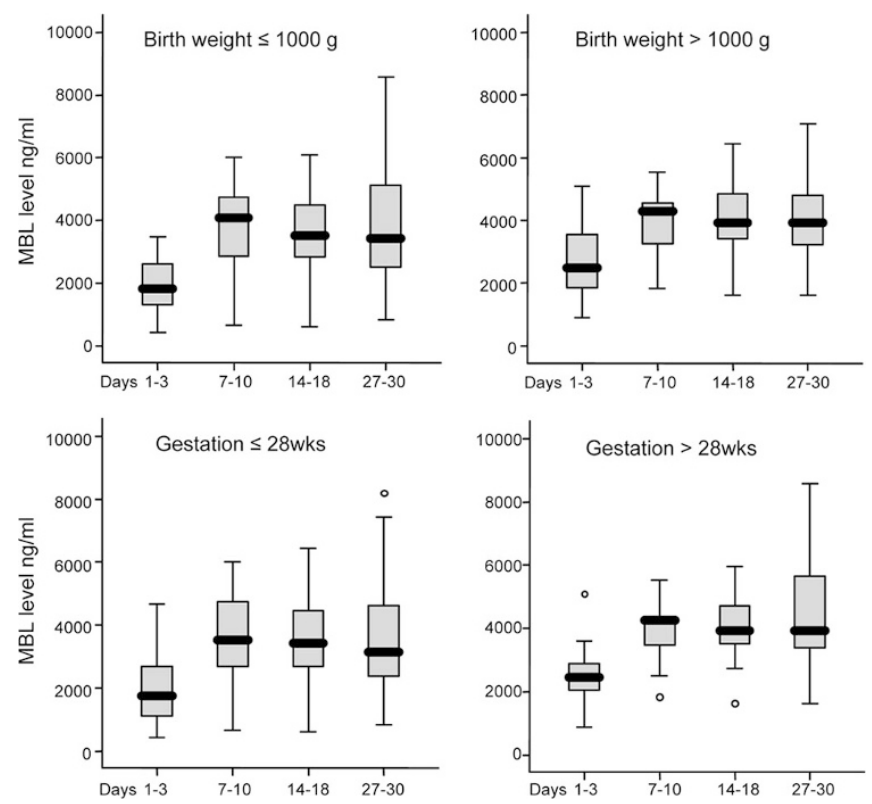

Figure 2. MBL levels in neonates with a wild-type MBL genotype in relation to postnatal age. The box plots show MBL levels $(\mathrm{ng} / \mathrm{mL})$ for birth weight $(\leq 1000$ and $>1000 \mathrm{~g})$ and gestational ages ( $\leq 28$ and $>28 \mathrm{wk})$. Outliers are shown as black dots. Levels are expressed as mean \pm 2 SE. 

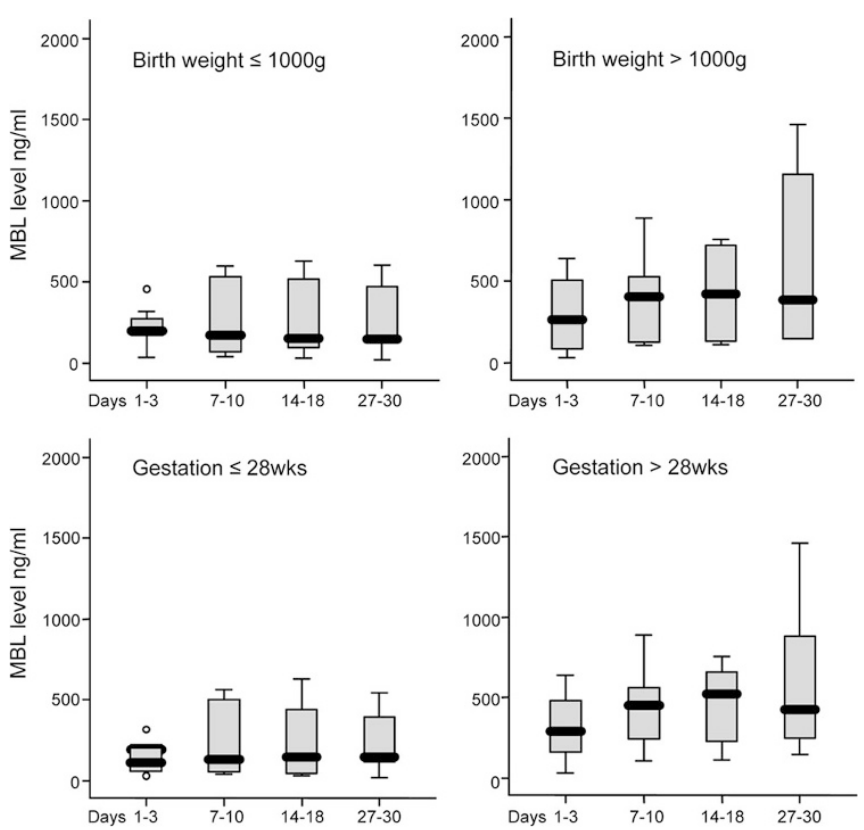

Figure 3. MBL levels in neonates with $\mathrm{MBL}$ variant alleles in relation to postnatal age. The box plots show MBL levels $(\mathrm{ng} / \mathrm{mL})$ for birth weight $(\leq 1000$ and $>1000 \mathrm{~g})$ and gestational ages $(\leq 28$ and $>28 \mathrm{wk})$. Outliers are shown as black dots. Levels are expressed as mean $\pm 2 \mathrm{SE}$.

neonates baseline MBL levels were significantly lower in neonates with a birth weight $\leq 1000 \mathrm{~g}$ (2099 versus 2654 $\mathrm{ng} / \mathrm{mL}, p=0.015$ ), or with gestational age $\leq 28 \mathrm{wk}$. This effect was not observed in neonates with MBL mutations (216 versus $441 \mathrm{ng} / \mathrm{mL}, p=0.43$ ). As with gestational age, the rate of change of MBL levels between the first and subsequent samples was marginally influenced by birth weight $(+62$ $\mathrm{ng} / \mathrm{mL} / \mathrm{d}, p=0.23)$. The independent effects of each variable were not distinguishable because birth weight and gestational age at birth were too highly correlated $(r=0.83, p<0.0001)$.

MBL phenotype and risk of sepsis. We looked at the risk of definitive sepsis in the 120 neonates with samples available for both MBL phenotyping and genotyping from the first $3 \mathrm{~d}$ after birth. From this group, 37 had definitive sepsis. In concordance with the analysis of the entire cohort, MBL genotype was not significantly associated with the risk of developing sepsis (Table 3). Phenotypic analysis, however, revealed that $52 \%$ of neonates with an MBL level of $\leq 400$ $\mathrm{ng} / \mathrm{mL}(n=27)$ (first quartile of the distribution), had sepsis compared with $26 \%, \mathrm{OR}=3.1, p=0.01$, in neonates with MBL levels of greater than $400 \mathrm{ng} / \mathrm{mL}$. The effect of low birth weight and low gestational age at birth in relation to MBL levels were then analyzed through a multivariable logistic regression model (Table 3). MBL level, low birth weight, and low gestational age remained independently associated with the risk of sepsis. The probability of sepsis in a neonate of $\leq 28 \mathrm{wk}$ or $\leq 1000 \mathrm{~g}$ with MBL levels $\leq 400 \mathrm{ng} / \mathrm{mL}$ was $70 \%$. With MBL levels above $400 \mathrm{ng} / \mathrm{mL}$, the risk of sepsis was $47 \%$ in both groups. Because of the high correlation between birth weight and gestational age, their independent effect could not be checked.

When looking at the risk of sepsis, definitive and presumed, there was still a trend toward a higher risk of sepsis in those with low MBL but this did not reach statistical significance (73\% if MBL $<400 \mathrm{ng} / \mathrm{mL}$ versus $57 \%$ if $\mathrm{MBL}$ was $\geq 400$ $\mathrm{ng} / \mathrm{mL}, \mathrm{OR}=2.0, p=0.11)$.

MBL status and duration of antibiotic therapy. In the British neonates, the duration of antibiotic therapy used in the first $30 \mathrm{~d}$ of life was recorded. Forty-seven neonates had both MBL genotype and phenotype measured in the first $3 \mathrm{~d}$ of life. Nineteen neonates received more than $10 \mathrm{~d}$ of antibiotics. Of these, 10 had one or more variant alleles. Of the 28 who received antibiotics for $10 \mathrm{~d}$ or less, 9 had $\mathrm{A} / \mathrm{O}$ or $\mathrm{O} / \mathrm{O}$ genotypes $(p=0.08)$. When antibiotic duration was related to MBL status, as determined by phenotype (Fig. 4), median MBL levels were found to be significantly lower in patients treated with antibiotics for more than $10 \mathrm{~d}$ compared with neonates receiving antibiotics for $10 \mathrm{~d}$ or less $(422 \mathrm{ng} / \mathrm{mL}$ versus $1618 \mathrm{ng} / \mathrm{mL}, p=0.02$ ). Three of the 9 neonates who had a WT genotype and who received more than $10 \mathrm{~d}$ of antibiotics had levels of less than $1000 \mathrm{ng} / \mathrm{mL}$. This was double the proportion ( 3 of 19) of WT neonates with MBL levels of $1000 \mathrm{ng} / \mathrm{mL}$ or less and who received antibiotics for less than $10 \mathrm{~d}$.

\section{DISCUSSION}

This is the first study to look in detail at MBL genotype, MBL levels, and susceptibility to infection in premature neonates. The most important finding was that babies who were

Table 3. Risk of definitive sepsis depending on MBL genotype, phenotype, gestational age (GA) and birth weight (BW)

\begin{tabular}{|c|c|c|c|c|c|}
\hline Factor & Patients $(n=120)$ & Definitive sepsis (\%) & Unadjusted & Multivariable model 1 & Multivariable model 2 \\
\hline MBL genotype & & & $(p=0.33)$ & & \\
\hline $\mathrm{A} / \mathrm{A}$ & 77 & 29 & 1 & & \\
\hline $\mathrm{A} / \mathrm{O}$ and $\mathrm{O} / \mathrm{O}$ & 43 & 37 & 1.48 & & \\
\hline$>400 \mathrm{ng} / \mathrm{ml}$ & 93 & 26 & 1 & 1 & 1 \\
\hline$\leq 400 \mathrm{ng} / \mathrm{ml}$ & 27 & 52 & 3.1 & 2.9 & 2.7 \\
\hline BW & & & $(p=0.0006)$ & $(p=0.001)$ & - \\
\hline GA & & & $(p<0.001)$ & & $(p<0.003)$ \\
\hline$>28$ wks & 87 & 23 & 1 & & 1 \\
\hline$\leq 28 \mathrm{wks}$ & 33 & 55 & 4.0 & & 3.7 \\
\hline
\end{tabular}

Uni- and multivariable analysis; $n=120$. 


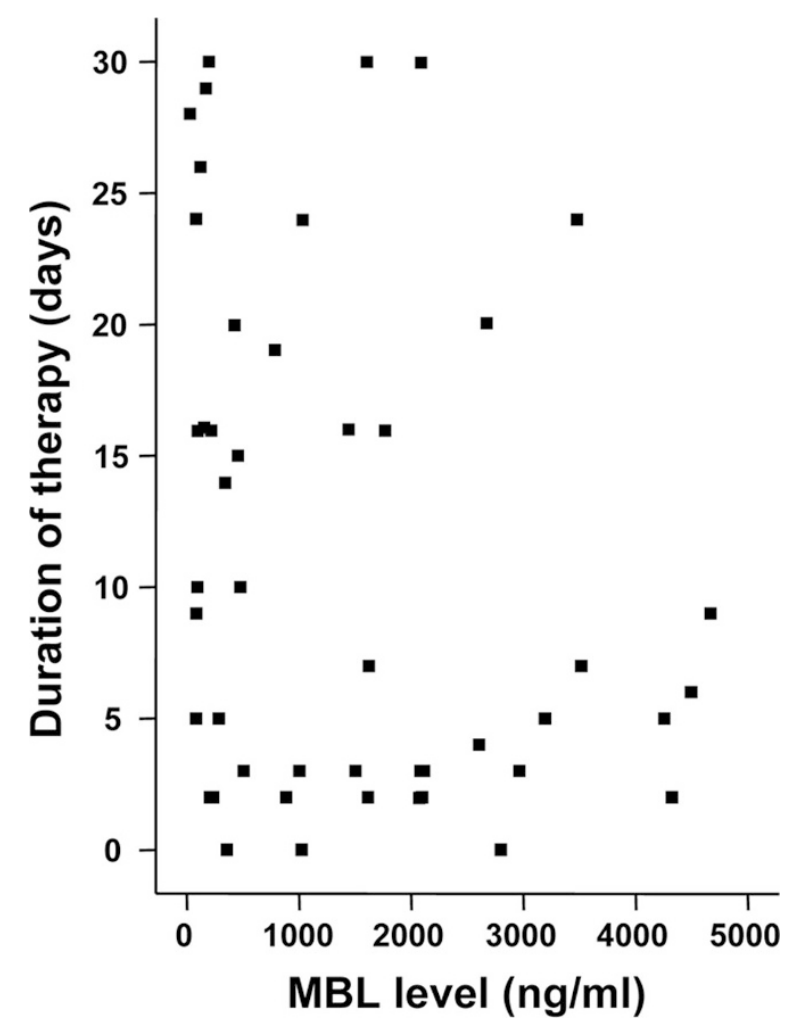

Figure 4. Relationship between MBL levels and duration of antibiotic therapy in the British cohort MBL levels were lower in neonates treated with antibiotics for more than $10 \mathrm{~d}$ compared with neonates receiving antibiotics for $10 \mathrm{~d}$ or less $(p=0.02)$.

less than $1000 \mathrm{~g}$ or born at less than $28 \mathrm{wk}$ who had low MBL levels $(<400 \mathrm{ng} / \mathrm{mL})$ were more likely to suffer from sepsis.

A recent article has also found an association between low MBL levels and an increased risk of sepsis (36). In this study, nearly half of the positive blood cultures grew Klebsiella pneumoniae. The rate of proven sepsis to non-Coagulase negative staphylococci organisms in our study was much lower. This may be due to differences in the environment, the microbial etiology of sepsis and supportive care practice between centers. However, it would seem that MBL is still operating to protect neonates from sepsis in these different settings. In both studies, the key observation was that MBL was influencing the rate of bacteraemia. In our study, the significance of the MBL effect was lost when presumed sepsis (i.e., without a positive blood culture) was included in the analyses. This indicates that MBL is likely to be influencing host bactericidal properties, probably through activation of complement pathways (37). Such an explanation is thought to explain why MBL deficient mice are more likely to succumb to Staphylococcus aureus and Pseudomonas infections (38). In addition, MBL may also be modulating the host's response to a bacterial challenge. In a recent study of children with systemic inflammatory response syndrome (SIRS), MBL deficiency was highly correlated with the development of systemic inflammatory response syndrome (26). This was not apparently due to an increase in invasive bacterial infections. It has now been established that MBL can modulate cytokine production in vitro and in vivo and this may influence the response of neonates to even minor infections (39).
In previous studies, gestational age and birth weight were found to markedly influence MBL levels (29-31). We found that the most important effect was postnatal age. As Figures 2 and 3 demonstrate, MBL levels were low at birth and increased significantly in WT neonates during the first week of life. There was also an effect of gestational age or birth weight, but only in wild type neonates of less than $1000 \mathrm{~g}$ or of $28 \mathrm{wk}$ gestation. MBL is synthesized by hepatocytes and seems to show a similar developmental pattern to that of other proteins synthesized by the liver. The significance of this finding, also highlighted by Frakking, is that even neonates with a WT genotype may be deficient in MBL at birth (31). Indeed, in our study, genotype alone did not significantly influence the rate of sepsis. It was only when MBL levels were analyzed, that a correlation between low MBL levels and sepsis emerged. We chose a level of $400 \mathrm{ng} / \mathrm{mL}$ as our cutoff for two reasons. First, in a study of MBL levels and genotypes from over 500 children from the Avon longitudinal study of Parents and Children, individuals who were either $\mathrm{YO} / \mathrm{YO}$ or $\mathrm{XA} / \mathrm{YB}$ or $\mathrm{XA} / \mathrm{YC}$ all had levels of less than $400 \mathrm{ng} / \mathrm{mL}$ (unpublished data). Second, in previous studies we found that MBL levels below $400 \mathrm{ng} / \mathrm{mL}$ did not activate complement binding and did not enhance MBL-mediated opsonophagocytosis (37).

The reasons why genotype analyses did not reveal a significant association with sepsis are because it underestimated the number of neonates who had levels of less than $400 \mathrm{ng} / \mathrm{mL}$. Indeed the number of neonates who were $\mathrm{YO} / \mathrm{YO}, \mathrm{XA} / \mathrm{YB}$ or $\mathrm{XA} / \mathrm{YC}$, (i.e., the genotypes associated with levels below 400 $\mathrm{ng} / \mathrm{mL}$ in healthy children), was $10 \%$ (12 of 120). However, the proportion of neonates with levels of less than $400 \mathrm{ng} / \mathrm{mL}$ was higher at $23 \%$ (27 of 120). This is because nearly half of the neonates with YA/YO had levels below $400 \mathrm{ng} / \mathrm{mL}$ (Fig. 3). This significantly increased the number of premature neonates who were phenotypically extremely MBL deficient at birth.

The clinical effect of having low MBL levels at birth was also demonstrated in the analysis of antibiotic usage within WT neonates in the UK cohort. Six of the 28 WT neonates had MBL levels of less than $1000 \mathrm{ng} / \mathrm{mL}$. Half of these received more than $10 \mathrm{~d}$ of antibiotics. We consider antibiotic usage to be a marker of sepsis, as a course of at least $10 \mathrm{~d}$ of antibiotics was always administered for proven or presumed sepsis in the UK cohort. As such, it would seem that low levels of MBL even within the WT population could predispose neonates to sepsis.

This study demonstrates that MBL levels below $400 \mathrm{ng} / \mathrm{mL}$ treble the chances of developing sepsis. The combination of prematurity, gestation of $\leq 28 \mathrm{wk}$ or birth weight $\leq 1000 \mathrm{~g}$ and MBL levels $\leq 400 \mathrm{ng} / \mathrm{mL}$ increase the risk of sepsis to $70 \%$. Whereas, in the population of neonates with MBL levels above $400 \mathrm{ng} / \mathrm{mL}$, the risk of sepsis was less than 50\%. MBL will become available as a therapeutic agent in the near future and from our results, may be a useful adjunct to the care of premature neonates (40).

Acknowledgments. The authors thank Professors H. Tchorzewski and J. Wilczynski for approval of the study in Poland, the staff in the Infectious Diseases and Microbiology Unit, and 
Neonatal Units in Poland and the UK and Dr Angie Wade and Christina Drew for their statistical advice.

\section{REFERENCES}

1. Stoll BJ, Hansen N, Fanaroff AA, Wright LL, Carlo WA, Ehrenkranz RA, Lemons JA, Donovan EF, Stark AR, Tyson JE, Oh W, Bauer CR, Korones SB, Shankaran S, Laptook AR, Stevenson DK, Papile LA, Poole WK 2002 Late-onset sepsis in very low birth weight neonates: the experience of the NICHD Neonatal Research Network. Pediatrics 110:285-291

2. Palazzi DL, Klein JO, Baker CJ 2005 Bacterial sepsis and meningitis. In: Remington J, Klein J, Baker C, Wilson C (eds) Infectious Diseases of the fetus and newborn infant, 6th edition. Elsevier Saunders, Philadelphia, pp 247-296

3. Stoll BJ, Hansen NI, Higgins RD, Fanaroff AA, Duara S, Goldberg R, Laptook A, Walsh M, Oh W, Hall E 2005 Very low birth weight preterm infants with early onset neonatal sepsis: the predominance of gram-negative infections continues in the National Institute of Child Health and Human Development Neonatal Research Network 2002-2003. Pediatr Infect Dis J 24:635-639

4. Sandberg K, Fasth A, Berger A 2000 Preterm infants with low immunoglobulin G levels have increased risk of neonatal sepsis but do not benefit from prophylactic immunoglobulin G. J Pediatr 137:623-628

5. Luck S, Torny M, d'Agapeyeff K 2003 Estimated early-onset group B streptococcal neonatal disease. Lancet 361:1953-1954

6. Christensen KK, Christensen P, Duc G 1984 Correlation between serum antibodylevels against group B streptococci and gestational age in newborns. Eur J Pediatr 142:86-88

7. Lin FY, Philips JB, Azimi PH 2001 Level of maternal antibody required to protect neonates against early-onset disease caused by group B Streptococcus type Ia: a multicenter, seroepidemiology study. J Infect Dis 184:1022-1028

8. Geelen SP, Fleer A, Bezemer AC 1990 Deficiencies in opsonic defense to pneumococci in the human newborn despite adequate levels of complement and specific IgG antibodies. Pediatr Res 27:514-518

9. Schibler KR, Liechty KW, White WL, Christensen RD 1993 Production of granulocyte colony-stimulating factor in vitro by monocytes from preterm and term neonates. Blood 82:2478-2484

10. Turner MW 2003 The role of mannose-binding lectin in health and disease. Mol Immunol 40:423-429

11. Jack DL, Turner MW 2003 Anti-microbial activities of mannose-binding lectin Biochem Soc Trans 31:753-757

12. Gadjeva M, Takahashi K, Thiel S 2004 Mannan-binding lectin-a soluble pattern recognition molecule. Mol Immunol 41:113-121

13. Ezekowitz RA, Shi L, Fraser I, Takahashi K 2005 The mannose-binding lectin: an infection susceptibility gene. Adv Exp Med Biol 560:99-103

14. Neth O, Jack DL, Dodds AW, Holzel H 2000 Mannose-binding lectin binds to a range of clinically relevant microorganisms and promotes complement deposition. Infect Immun 68:688-693

15. Tenner AJ, Robinson SL, Ezekowitz RA 1995 Mannose binding protein (MBP) enhances mononuclear phagocyte function via a receptor that contains the 126,000 M (r) component of the C1q receptor. Immunity 3:485-493

16. Jack DL, Klein NJ, Turner MW 2001 Mannose-binding lectin: targeting the microbial world for complement attack and opsonophagocytosis. Immunol Rev 180:86-99

17. Petersen SV, Thiel S, Jensenius JC 2001 The mannan-binding lectin pathway of complement activation: biology and disease association. Mol Immunol 38:133-149

18. Turner MW, Lipscombe RJ, Levinsky RJ 1993 Mutations in the human mannose binding protein gene: their frequencies in three distinct populations and relationship to serum levels of the protein. Immunodeficiency 4:285-287

19. Lipscombe RJ, Sumiya M, Summerfield JA, Turner MW 1995 Distinct physicochemical characteristics of human mannose binding protein expressed by individuals of differing genotype. Immunology 85:660-667
20. Madsen HO, Garred P, Thiel S, Kurtzhals JA, Lamm LU, Ryder LP, Svejgaard A 1995 Interplay between promoter and structural gene variants control basal serum level of mannan-binding protein. J Immunol 155:3013-3020

21. Madsen HO, Satz ML, Hogh B, Svejgaard A, Garred P 1998 Different molecular events result in low protein levels of mannan-binding lectin in populations from southeast Africa and South America. J Immunol 161:3169-3175

22. Summerfield JA, Sumiya M, Levin M, Turner MW 1997 Association of mutations in mannose binding protein gene with childhood infection in consecutive hospital series. BMJ 314:1229-1232

23. Koch A, Melbye M, Sorensen P 2001 Acute respiratory tract infections and mannose-binding lectin insufficiency during early childhood. JAMA 285:1316-1321

24. Neth O, Hann I, Turner MW, Klein NJ 2001 Deficiency of mannose-binding lectin and burden of infection in children with malignancy: a prospective study. Lancet 358:614-618

25. Eisen DP, Minchinton RM 2003 Impact of mannose-binding lectin on susceptibility to infectious diseases. Clin Infect Dis 37:1496-1505

26. Fidler KJ, Wilson P, Davies JC, Turner MW, Peters MJ, Klein NJ 2004 Increased incidence and severity of the systemic inflammatory response syndrome in patients deficient in mannose-binding lectin. Intensive Care Med 30:1438-1445

27. Terai I, Kobayashi K 1993 Perinatal changes in serum mannose-binding protein (MBP) levels. Immunol Lett 38:185-187

28. Thiel S, Bjerke T, Hansen D, Poulsen LK, Schiotz PO, Jensenius JC 1995 Ontogeny of human mannan-binding protein, a lectin of the innate immune system. Pediatr Allergy Immunol 6:20-23

29. Lau YL, Chan SY, Turner MW 1995 Mannose-binding protein in preterm infants developmental profile and clinical significance. Clin Exp Immunol 102:649-654

30. Hilgendorff A, Schmidt R, Bohnert A 2005 Host defence lectins in preterm neonates. Acta Paediatr 94:794-799

31. Frakking FN, Brouwer N, Zweers D, Merkus MP, Kuijpers TW, Offringa M, Dolman KM 2006 High prevalence of mannose-binding lectin (MBL) deficiency in premature neonates. Clin Exp Immunol 145:5-12

32. Jack D, Bidwell J, Turner M, Wood N 1997 Simultaneous genotyping for all three known structural mutations in the human mannose-binding lectin gene. Hum Mutat 9:41-46

33. Turner MW, Dinan L, Heatley S, Jack DL, Boettcher B, Lester S, McCluskey J, Roberton D 2000 Restricted polymorphism of the mannose-binding lectin gene of indigenous Australians. Hum Mol Genet 9:1481-1486

34. Dzwonek A, Novelli V, Bajaj-Elliott M, Turner M, Clapson M, Klein N 2006 Mannose-binding lectin in susceptibility and progression of HIV-1 infection in children. Antivir Ther 11:449-505

35. Laird NM, Ware JH 1982 Random-effects models for longitudinal data. Biometrics 38:963-974

36. De Benedetti F, Auriti C, D’Urbano LE, Ronchetti MP, Rava L, Tozzi A, Ugazio AG, Orzalesi MM 2007 Low serum levels of mannose binding lectin are a risk factor for neonatal sepsis. Pediatr Res 61:325-328

37. Neth O, Jack DL, Johnson M, Klein NJ, Turner MW 2002 Enhancement of complement activation and opsonophagocytosis by complexes of mannose-binding lectin with mannose-binding lectin-associated serine protease after binding to Staphylococcus aureus. J Immunol 169:4430-4436

38. Shi L, Takahashi K, Dundee J, Shahroor-Karni S, Thiel S, Jensenius JC, Gad F, Hamblin MR, Sastry KN, Ezekowitz RA 2004 Mannose-binding lectin-deficient mice are susceptible to infection with Staphylococcus aureus. J Exp Med 199:13791390

39. Jack DL, Read RC, Tenner AJ, Frosch M, Turner MW, Klein NJ 2001 Mannosebinding lectin regulates the inflammatory response of human professional phagocytes to Neisseria meningitidis serogroup B. J Infect Dis 184:1152-1162

40. Valdimarsson H, Vikingsdottir T, Bang P, Saevarsdottir S, Gudjonsson JE, Oskarsson O, Christiansen M, Blou L, Laursen I, Koch C 2004 Human plasma-derived mannose-binding lectin: a phase I safety and pharmacokinetic study. Scand J Immunol 59:97-102 